\title{
25 Research Square \\ Designing and Theoretical study of fluorinated small molecule donor materials for organic solar cells
}

\section{Usama Mubashar}

University of Agriculture Faisalabad

\section{Afifa Farhat}

University of Agriculture Faisalabad

Rasheed Ahmad Khera ( $\nabla$ rasheedahmadkhera@yahoo.com )

University of Agriculture, Faisalabad, Pakistan https://orcid.org/0000-0002-5513-8096

\section{Rabia Saleem}

University of Agriculture Faisalabad

Javed IQBAL

University of Agriculture Faisalabad

\section{Research Article}

Keywords: Benzodithiophene, DFT, Reorganization energy, Binding energy. TDM

Posted Date: April 7th, 2021

DOI: https://doi.org/10.21203/rs.3.rs-302537/v1

License: (c) (1) This work is licensed under a Creative Commons Attribution 4.0 International License. Read Full License 


\section{Abstract}

A recently synthesized photoactive donor named fluorinated thienyl substituted benzodithiophene (DRTBFT), modified with four novel end capped acceptor molecules, have been investigated through different electrical, quantum and spectrochemical techniques for their enhanced electro-optical and photovoltaic properties. DRTB-FT was connected to 2-methylenemalononitrile (D-1), 2-methylene-3-oxobutanenitrile (D2), 2-(2-methylene-3-oxo-2,3-dihydro-1 H-inden-1-ylidene) malonitrile (D-3) and 3-methyl-5methylene-2thioxothiazolidin-4-one (D-4) as terminal acceptor moieties. The architectural D-1 and D-3 molecules owe reduced optical band gap of 2.45 and $2.28 \mathrm{eV}$ benefited from A-D-A configuration and have broaden maximum absorption band $\left(\lambda_{\max }\right)$ at 617 and $602 \mathrm{~nm}$ in polar organic solvent (chloroform). Reduced optical band gap set the ease for enhanced absorption. Reorganization energy of electron $\left(\lambda_{e}\right)$ of D-3 molecule $(0.00397 \mathrm{eV})$ was smaller amongst all which disclosed its greater mobility of conducting electrons (ICT). Larger values of dipole moment ( $\boldsymbol{\mu})$ of D-1(5.939 Debye) and D-3 (3.661 Debye) molecules in comparison to $\mathbf{R}$ indicated greater solubilities of the targeted molecules. Among the tailored

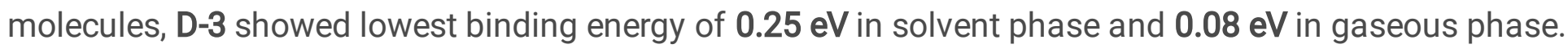
The voltaic strength of designed molecules was examined with respect to fullerene derivative $\left(\mathrm{PC}_{61} \mathrm{BM}\right)$ which exposed that D-1 is the best choice for achieving higher PCE. TDM (transition density matrix), DOS (density of states) analysis and binding energies all were estimated at MPW1PW91/6-31G (d, p) level of DFT (density functional theory).

\section{Introduction}

The world is facing serious energy shortfalls as a result of escalating energy demands due to rapid industrialization, enhancements in lifestyle and increase in population [1-3]. Though much of the energy requirements are being fulfilled by non-renewable energy resources such as fossil fuels (petroleum fractions, natural gas and coal) [4-6] but the reserves of these non-renewable resources are being continuously depleting $[7,8]$. Moreover, they have posed some glaring consequences to environment due to emission of $\mathrm{CO}_{2}$ during combustion and to humans by creating an imbalance between energy needs and supply $[9,10]$. In short, we will soon run out of these exhaustible energy sources [11]. Scientist are endeavoring to find the substitutes which are not only cost effective but triumph in minimizing the energy gap between demand and supply[12-14].

Various renewable energy resources like solar energy, tidal energy, biomass, wind energy and etc. are potential candidates to be used as substitutes for fossil fuels[14-16]. Amongst these, solar energy being environmentally amiable, harnessed through sun using photovoltaics has been considered a smart choice $[17,18]$. Although single crystalline, multi-crystalline and amorphous inorganic systems have obtained reliable efficiency levels of the order of $25 \%$ yet these have various shortcomings including uneconomical fabrication, resource scarcity of the required material, less thermal stability and brittleness $[16,18,19]$. After their serendipitous discovery, organic photovoltaics have been extensively investigated owing to remarkable features like solution processability, structural diversity, flexibility, low weight, 
transparency, cost effectiveness and easy control of energy levels in contradiction to inorganic photovoltaics[20-23]. Great advances have been made over years in the device design and applications of polymer and small molecules based bulk heterojunction photovoltaic devices [23, 24]. Organic photovoltaics (OPVs) generally comprised of donor conjugated polymers, oligomers and conjugated pigments, blended with fullerene derivatives (acting as acceptors) in bulk heterojunctions [23, 25-27]. These are well known for their optical properties, efficient charge transfer abilities, and remarkable efficiencies in the range of $10-12 \%[28-30]$.

Investigations explore that, Naphthalene and perylene based diimides (NDI and PDI) as acceptor moieties in various bulk heterojunctions have shown power conversion efficiencies of 16 and $17.23 \%$ respectively $[31,32]$. Non-fullerene organic acceptors have successfully replaced the fullerene derivatives on account of their large scale production, commercialization, better morphology, photostability and improved PCE of the order of $14-17 \%$ for single junction and two terminal (2T) tandem OPVs [33].

An effective strategy for broadening of optical absorption is to improve the intramolecular push pull effect. Yong Cui and coworkers employed a useful molecular design strategy by introducing halogen atom into non-fullerene end capped acceptor moieties which reduced the band gap, broaden the optical absorption and caused significant increase in charge mobility and open circuit voltage due to less nonradiative energy loss which in turn boost the power conversion efficiency to $16.5 \%[34]$.

All small molecule and all polymer based organic photovoltaics have been investigated for their photovoltaic and electro-optical properties. When small acceptor molecule is blended with small donor molecule, give rise to all small molecule organic solar cell (AS-OSC) and when polymer donor moiety is blended with polymer acceptor it is named as all polymer OSC (AP-OSC)[35]. Recently, Chunyan Liu et al., synthesized a small photoactive donor DRTB-FT by substituting fluorothienyl into benzodithiophene core and investigated it both experimentally and theoretically. A lower HOMO bonding molecular orbital wavefunction of $-5.64 \mathrm{eV}$ and a high open circuit voltage of $1.07 \mathrm{~V}$ was attained with $7.66 \%$ power conversion efficiency which was attributed to the fluorination of molecule [36].

Being influenced from the above findings, currently a series of molecules in A-D-A configuration have been designed in which fluorinated thienyl substituted benzodithiophene donor core (DRTB-FT) is connected to 2-methylenemalononitrile for D-1, 2-methylene-3-oxobutanenitrile for D-2, 2-(2-methylene-3oxo-2,3-dihydro-1 H-inden-1-ylidene) malonitrile for D-3 and 3-methyl-5methylene-2-2thioxothiazolidin-4one in D-4 as terminal acceptor moieties (Fig. 1). These modified molecules were then investigated for their structure-property relationships, photophysical processes, optical and photovoltaic properties through different quantum chemical, electronic and spectroscopic techniques. Geometrical parameters were also examined like HOMO and LUMO delocalization effects, DOS (density of states), solution processability in polar solvents, reorganization energies and maximum voltage at zero current level $\left(\mathrm{V}_{o c}\right)$.

\section{Designed And Investigated Molecules}




\section{Computational Details}

Gauss view 5.0 [37] was used for construction of reference R and designed molecules D-1, D-2, D-3 and D4 and to envisage the outcomes of quantum chemical investigations. For geometry optimization of reference molecule $\mathbf{R}$ and designed molecules D-1-D-4, GAUSSIAN 09[38] program package was employed. First of all, geometrical optimization and frequency studies of molecule $\mathbf{R}$ were executed with a range of density functional methods such as B3LYP[39], CAM-B3LYP[40], MPW1PW91[41] and WB97XD[42] for the quest to choose the method whose maximum absorbance is in better agreement with the experimental maximum absorption $\left(\lambda_{\max }=541 \mathrm{~nm}\right)$ [36]. The outcomes confirm that the experimental results are in better agreement with density functional theory (DFT) results $\left(\lambda_{\max }=578 \mathrm{~nm}\right)$ at MPW1PW91/631-G $(\mathrm{d}$, p) level in chloroform solvent indicated in the Fig. 6(a). Since, the functional (MPW1PW91) having more agreement of absorption maxima value with experimental $\lambda_{\max }$ value so, it was chosen for further calculations. The integral equation formalism polarizable continuum model (IEFPCM) [42] has been utilized to check the effect of solvent on the absorption maxima value. For plotting data and graphical representation of data origin 6.0 software [43] has been employed. Frontier molecular orbitals (FMO), density of state (DOS) and transition density matrix (TDM) analysis have been done for charge dispersion and contribution of different moieties to the total absorption[44], with the same functional at the same level of theory. DOS and TDM maps have been plotted by PyMOlyze 1.1[45] and Multiwfn 3.3.9 Revision software [46] accordingly. Charge mobilities and dipole moments $(\mu)$ were calculated with MPW1PW91 functional together with 631-G $(d, p)$ basis set. Reorganization energies of electrons $\left(\lambda_{e}\right)$ and holes $\left(\lambda_{h}\right)$ were then calculated from the single point energy calculations and energy calculations after optimization of cations and anions as explained in Eqs. (1) and (2) given below[47].

$\lambda_{e}=\left[E_{0}^{-}-E_{-}\right]+\left[E_{-}^{0}-E_{0}\right](1)$

$\lambda_{h}=\left[E_{0}^{+}-E_{+}\right]+\left[E^{0}+E_{0}\right](2)$

In the above equation where $E_{0}{ }^{-}$is the energy of anion of neutral geometry, $E_{0}{ }^{+}$is the energy of cation of neutral geometry and $E_{0}$ is the energy of neutral molecule. $E_{-}$is energy of anion in ionic geometry and $\mathrm{E}_{+}$ is energy of cation in ionic geometry. $E_{+}^{0}$ and $E^{0}$ are neutral energies in ionic state (cation and anion) after optimization. All the above-mentioned parameters were calculated and visualized from fully optimized and kinetically stable geometries of the molecules (D-1-D-4) shown in the Fig. 2.

\section{Results And Discussion}

Fluorinated all small molecule (DRTB-FT) based four non-fullerene donor molecules (D-1-D-4) have been constructed with A-D-A configuration. Optimization of internal geometries and investigation of optical and photovoltaic properties such as maximum absorption $\left(\lambda_{\max }\right)$ in chloroform solvent, HOMO-LUMO 
energy gap, dipole moment, charge mobilities and oscillator strength were investigated with MPW1PW91/6-31G (d, p) level of density functional theory.

\subsection{Frontier Molecular orbitals (FMOs)}

Quantum mechanical investigation of frontier molecular orbitals is an important tool for electronic excitation properties analysis. Time dependent-density functional theory well explain these properties. Planer configurations, extended- $\pi$-conjugation and introduction of electron donating or withdrawing moieties are the strategies that lead to the significant charge mobilities, narrowing of energy band gap and better absorption properties due to increase in $\lambda_{\max }$ value of molecules[48]. These mechanisms enhance the electron donating ability of HOMO by raising the energy level of the occupied orbitals and accepting abilities of LUMO by lowering the energy level of the unoccupied orbitals which may prove useful in enhancement of delocalization of $\pi$ electrons on the FMO. Charge flow pattern of reference molecule $\mathbf{R}$ and designed structures $\mathbf{D}-1-\mathbf{D}-\mathbf{4}$ are shown in Fig. 3.

HOMO of reference molecule $\mathbf{R}$ is uniformly distributed on the donor core, while LUMO is homogeneously dispersed all over the molecule showing the less delocalization and wider energy band gap. Among the designed molecules D-1, D-2, D-3, and D-4, HOMO is more concentrated on donor core while the LUMOs have different pattern. LUMO of D-1, D-2 and D-4, to greater extent are dispersed on end capped acceptor moieties and to very less extent on the donor core. Massive delocalization can be seen on the LUMO of D-

3. The energy order of $E_{\text {HOMO }}$ bonding energy orbitals were found to be $-5.75(D-1)<-5.63(D-2)<-5.61(D-4)$ $<-5.57(D-3)<-5.48(R)$ and those of $E_{\text {LUMO }}$ were $-2.86(R)>-3.08(D-4)>-3.09(D-2)-3.29(D-3)>-3.30(D-1)$.

Energy band gap is a true replica of absorption and delocalization of electrons. Lesser the band gap, higher will be the delocalization and the molecule will move to the red shift (bathochromic effect). HOMOLUMO energy gap of reference and designed molecules arrange themselves in the order of 2.62 > 2.54>

$2.53>2.45>2.28$ for R, D-2, D-4, D-1 and D-3 respectively. The HOMO-LUMO energy gap, along with the energies of HOMO and LUMO of designed molecules and reference molecule are tabulated in Table 1 and their graphic description is in Fig. 4. All the designed molecules show lower energy band gap than reference molecule which lead to the better delocalization of electrons from HOMO to LUMO due to the comparatively strong withdrawing effect of end capped acceptor moieties. D-3 designed molecule has the lowest band gap of $\mathbf{2 . 2 8} \mathrm{eV}$ due to extended $\pi$ conjugation in the end capped acceptor moiety and negative inductive effect of 2-(2-methylene-3-oxo-2,3-dihydro-1 H-inden-1-ylidene)malonitrile. In tailored molecule D-1, cyano group act as pi-acceptor functionality removing electron density from adjacent pisystem. 
Table 1

Energies of HOMO and LUMO and the Energy band gap of $\mathbf{R}$ and designed D-1-D-4 molecules at MPW1PW91/6-31G** level of theory.

\begin{tabular}{|llll|}
\hline Molecule & $\begin{array}{l}\mathrm{E}_{\text {HOMO }} \\
(\mathrm{eV})\end{array}$ & $\begin{array}{l}\mathrm{E}_{\text {LUMO }} \\
(\mathrm{eV})\end{array}$ & Energy gap $\left(\mathrm{E}_{\mathrm{g}}\right)$ \\
\hline R & -5.48 & -2.86 & 2.62 \\
\hline D-1 & -5.75 & -3.30 & 2.45 \\
\hline D-3 & -5.63 & -3.09 & 2.54 \\
\hline D-4 & -5.57 & -3.29 & 2.28 \\
\hline
\end{tabular}

\subsection{Density of state Analysis}

Density of state analysis reinforce the results of frontier molecular orbitals (FMOs). Electron density of designed organic solar cell molecules were computed with PyMOlyze software suit. At particular energy level, DOS corresponds to number of different states of molecular orbital. With the aid of partial density of state contribution of each molecular orbital constituting the system, total density is analyzed. Individual contribution of principle fragments of a molecule (donor, acceptor and sometime spacer) to the total absorption band and electronic distribution are analyzed. Green lines indicate the maximum electron density on the donor core and red lines exhibit the same at acceptor moieties in the DOS graph.

For this reason, a molecule is fragmented into donor and acceptor fragments to check their individual contribution to the total absorption as indicated in Fig. 5. From DOS graph it is envisaged that the donor core of fluorine substituted benzodithiophene contribute significantly to the total population in reference $\mathrm{R}$ and each designed molecule.

The negative energy values side along $\mathrm{x}$-axis, corresponds to HOMO (valence band) while the positive energy values side along the same axis indicate LUMO (conduction band). Between the conduction and valence band is band gap $\left(E_{\mathrm{g}}\right)$. The HOMO the orbital contribution of donor part was much larger than acceptor moieties in all tailored molecules D-1-D-4 plus reference molecule R. LUMO of R has comparable effect of donor and acceptor moieties towards total absorption. In LUMO of D-1-D-4, the orbital contribution effect of acceptor moieties is dominant over donor part; and this effect is more pronounced in D-3 represented in Fig. 5.

\subsection{Opto-electronic properties}


Theoretical maximum absorbance $\left(\lambda_{\max }\right)$ for designed $\mathbf{D}-\mathbf{1}, \mathbf{D}-\mathbf{2}, \mathbf{D}-\mathbf{3}, \mathbf{D}-\mathbf{4}$ and $\mathbf{R}$ molecules were calculated for 10 states to better understand the electronic excitation from ground to excited state at MPW1PW91/6$31 \mathrm{G} * \star$ level of density functional theory in solvent phase. Chances of electronic transition (\% ETC) of the four designed and one reference molecules are $81 \%, 90 \%, 63 \%, 86 \%$ and $91 \%$ respectively in chloroform/IEFPCM conditions. Stability and de-stability of HOMO and LUMO have greater impact on electronic excitation between FMOs and \%ETC. Larger excitations are related to the less stable HOMO. On the other hand, stable LUMO accommodate electrons for prolonged period in the acceptor group which laid the foundation for maximum efficiency of the material. Maximum absorbance $\left(\lambda_{\max }\right)$ for designed $D$ 1, D-2, D-3, D-4 and R molecules were found to be $617 \mathrm{~nm}, 602 \mathrm{~nm}, 602 \mathrm{~nm}, 601 \mathrm{~nm}$ and $578 \mathrm{~nm}$ respectively. The increasing order of maximum absorbance $\left(\lambda_{\max }\right)$ is $578 \mathrm{~nm}<601 \mathrm{~nm}<602 \mathrm{~nm}=602$ $\mathrm{nm}<617 \mathrm{~nm}$ for $\mathrm{R}<\mathrm{D}-\mathbf{4}<\mathrm{D}-2=\mathrm{D}-3<\mathrm{D}-1$ respectively.

The best absorption properties have been seen for $\mathbf{D}-\mathbf{1}$ than reference molecule $\mathbf{R}$ and designed molecules due to extended $\pi$-conjugated system in methylene malononitrile end capped acceptor moieties which leads to $\pi \rightarrow \pi^{*}$ transition and has bathochromic effect in the visible region of the spectrum. It is also inferred that $\pi$ electrons show strong interaction with chloroform solvent on the account of polarity. Furthermore, oscillator strength in chloroform solvent varies from 1.4359 to $\mathbf{3 . 1 1 8 0}$. Oscillator strength is proportional to the probability that a photon will be absorbed during excitation from ground state to excited state. Oscillator strength is in direct relation with light harvesting efficiency (LHE). Comparison of oscillator strengths in solvent phase and gaseous phase expose that light harvesting efficiency is greater in solvent phase than in gaseous phase. Excitation energies of molecules were found to be in the range of 2.01-2.14 eV. Experimental and theoretical $\lambda_{\max }$ values, \%ETC, excitation energies and oscillator strength of designed and reference molecule in solvent and gaseous phase have been tabulated in the Tables 2 and 3 respectively. After computing the values in the range of $350-800 \mathrm{~nm}$ we obtain the simulated UV/Visible spectrum shown in Fig. 6.

Electronic transition redistribute the electron density making a molecule more polar in the excited state. And the polar excited states are stabilized by polar solvent (chloroform) causing a red shift in the absorption of molecule. By comparing maximum absorbance wavelength of designed and reference molecule both in solvent and gaseous phase we inferred that due to charge separation, polarity is created which is stabilized by polar solvent that causes a shift in the absorption. 
Table 2

Experimental and calculated $\lambda_{\max }$, oscillator strength, excitation energy $(\Delta \mathrm{E}), \%$ electronic transport contribution (ETC) from donor to acceptor using IEFPCM/Chloroform model are shown in detail.

\begin{tabular}{|llllll|}
\hline Molecules & $\begin{array}{l}\text { Experimental } \lambda_{\max } \\
(\mathrm{nm})\end{array}$ & $\begin{array}{l}\text { Calculated } \lambda_{\max } \\
(\mathrm{nm})\end{array}$ & $\begin{array}{l}\text { Oscillator } \\
\text { strength }\end{array}$ & $\begin{array}{l}\Delta \mathrm{E} \\
(\mathrm{eV})\end{array}$ & $\% \mathrm{ETC}$ \\
\hline $\mathrm{R}$ & 541 & 578 & 3.1180 & 2.14 & $\mathrm{H} \rightarrow \mathrm{L}$ \\
& & & & & $(91 \%)$ \\
$\mathrm{D}-1$ & - & 617 & 2.8971 & 2.01 & $\mathrm{H} \rightarrow \mathrm{L}$ \\
& & & & & $(81 \%)$ \\
\hline $\mathrm{D}-2$ & - & 602 & 3.0422 & 2.06 & $\mathrm{H} \rightarrow \mathrm{L}$ \\
& & & & & $(90 \%)$ \\
\hline D-3 & - & 602 & 1.4359 & 2.03 & $\mathrm{H} \rightarrow \mathrm{L}$ \\
& & & & & $(63 \%)$ \\
\hline D-4 & - & 601 & 3.1508 & 2.07 & $\mathrm{H} \rightarrow \mathrm{L}$ \\
\end{tabular}

Table 3

Experimental and calculated $\lambda_{\max }$ oscillator strength, excitation energy $(\Delta E), \%$ electronic transport contribution (ETC) from donor to acceptor in gaseous phase are shown in detail.

\begin{tabular}{|llllll|}
\hline Molecules & $\begin{array}{l}\text { Experimental } \lambda_{\max } \\
(\mathrm{nm})\end{array}$ & $\begin{array}{l}\text { Calculated } \lambda_{\max } \\
(\mathrm{nm})\end{array}$ & $\begin{array}{l}\text { Oscillator } \\
\text { strength }\end{array}$ & $\begin{array}{l}\Delta \mathrm{E} \\
(\mathrm{eV})\end{array}$ & $\%$ ETC \\
\hline R & 541 & 556 & 2.8420 & 2.23 & $\mathrm{H} \rightarrow \mathrm{L}$ \\
& & & & 2.09 & $\mathrm{H} \rightarrow \mathrm{L}$ \\
$\mathrm{D}-1$ & - & 591 & 2.6136 & & $(93 \%)$ \\
\hline D-2 & - & 574 & & 2.16 & $\mathrm{H} \rightarrow \mathrm{L}$ \\
& & & 2.8403 & & $(93 \%)$ \\
\hline D-3 & - & 574 & 1.4720 & 2.20 & $\mathrm{H} \rightarrow \mathrm{L}$ \\
& & & & & $(76 \%)$ \\
\hline D-4 & - & 573 & 2.9327 & 2.16 & $\mathrm{H} \rightarrow \mathrm{L}$ \\
& & & & & $(88 \%)$ \\
\hline
\end{tabular}




\subsection{Reorganization energy (RE)}

Reorganization energies (energy required to structurally reorganize donor and acceptor upon electron transfer) of electron and hole are significant measure of charge transfer process. DFT method at MPW1PW91/6-31G** basis set was employed to investigate the (exciton) electron and hole transport properties. Reorganization energies are influenced by molecular packing, substituent effect of the end capped moieties, extended delocalization of charge. Marcus theory explains that two parameters (i) internal reorganization energy and (ii) external reorganization energy are to be considered to estimate reorganization energy of exciton[49]. Actually, charge separation take place when photon of light is absorbed that ensures the transformation of absorbed photon's energy into charge transfer energy. Larger values of reorganization energy correspond to greater change in structure when electrons get transported from the donor end to acceptor end or from neutral molecule to ionic one. RE determines longevity of charge separated states. Smaller values of RE of electron and larger driving force for reversal of excited state electron transfer (restoring the donor and acceptor to their ground state) leads to the longevity of charge separated state. Hence, better is the utility of such materials (D-1-D-4) in the OSCs. Reorganization energy has an indirect relation with charge transfer. Smaller the value of reorganization energy the more efficiently charge will be transferred.

Table 4

Simulated reorganization energy (RE) of electron and hole at MPW1PW91/6-31G basis set.

\begin{tabular}{|lll|}
\hline Molecule & $\lambda_{\mathrm{e}}(\mathrm{eV})$ & $\lambda_{\mathrm{h}}(\mathrm{eV})$ \\
\hline R & 0.00572 & 0.00553 \\
\hline D-1 & & \\
\hline D-3 & 0.00648 & 0.00611 \\
\hline D-4 & 0.00749 & 0.00622 \\
& 0.00397 & 0.00624 \\
\hline
\end{tabular}

Reorganization energies of electron $\left(\lambda_{e}\right)$ of all molecules were found to be in the order of $0.00397 \mathrm{eV}<$ $0.00572 \mathrm{eV}<0.00648 \mathrm{eV}<0.00731 \mathrm{eV}<0.00749 \mathrm{eV}$ for D-3, R, D-1, D-4 and D-2 respectively. Amongst all the molecules, only D-3 designed molecule has lowest reorganization energy which favor good charge transfer rate and charge transfer properties. While the reorganization energies of hole $\left(\lambda_{h}\right)$ were 0.00553 
$\mathrm{eV}<0.00611 \mathrm{eV}<0.00612 \mathrm{eV}<0.00622 \mathrm{eV}<0.00624 \mathrm{eV}$ for R, D-1, D-4, D-2 and D-3 respectively. These results suggest that the designed molecules $\mathrm{D}-\mathbf{1}$ to $\mathrm{D}-\mathbf{4}$ are better for hole transport as their reorganization energies of hole are comparable to $\mathbf{R}$ whereas, designed molecule $\mathbf{D}-\mathbf{3}$ is the best choice for electron transport in OSCs as its $\lambda_{\mathrm{e}}$ value is smallest among all others. Reorganization energies of electron and hole are summarized in Table 4.

\subsection{Dipole moment}

Dipole moment values are the estimation of polarity and extent of symmetry in the geometry of molecules. We can assess that lower values of dipole moment are due the larger symmetry present in the molecule. During excitation electrons get excited from the ground state to the excited state. So, there is unsymmetrical distribution of electron that makes the excited state more polar. Excited state being less stable, electrons return to the ground state configuration. Dipole moment of a molecule is the measure of solubility of the molecule in polar solvents. Greater are the values of dipole moment more will be the solubility that facilitate the solution processability of organic solar cell materials. Charge transfer abilities of organic solar material also greatly influenced by the dipole moment. Electronic excitation and dipole moment are proportional to each other. A comparison of ground state dipole moment $\left(\mu_{\mathrm{g}}\right)$ and excited state dipole moment $\left(\mu_{\mathrm{e}}\right)$ is shown in Table 5 . We have assessed the excited state dipole moment of molecules in polar chloroform solvent using IEFPCM model at MPW1PW91/6-31G** basis level of density functional theory.

During simulation analysis all the designed molecules show greater solubilities in polar organic chloroform solvent. Apart from this, dipole moment values in excited states are even greater than ground state that are attributed to the greater polarity due to electronic excitation and charge separation. The increasing order of solubilities at ground state is given as 0.853 Debye $(\mathbf{R})<1.556$ Debye $(\mathbf{D}-\mathbf{4})<2.456$ Debye (D-2) < 3.661 Debye (D-3) < 5.939 Debye (D-1) while in excited state the same order 1.072 Debye $(R)<2.050$ Debye $(D-4)<2.654$ Debye $(D-2)<4.463$ Debye $(D-3)<7.455$ Debye $(D-1)$ is followed but with increased solubilizing strengths. D-1 shows maximum dipole moment value that is attributed to the more polar cyanide moieties of end capped acceptor groups. Introduction of fluorine atoms (fluorination) also leads to the greater change in dipole moment[50]. 
Table 5

Strength of dipole moment in ground state $\left(\mu_{\mathrm{g}}\right)$ and excited state $\left(\mu_{\mathrm{e}}\right)$ and their difference in chloroform solvent using IEFPCM model.

\begin{tabular}{|llll|}
\hline Molecule & $\mu_{\mathrm{g}}(\mathrm{D})$ & $\mu_{\mathrm{e}}(\mathrm{D})$ & $\mu_{\mathrm{e}}-\mu_{\mathrm{g}}(\mathrm{D})$ \\
\hline R & 0.853 & 1.072 & 0.219 \\
\hline D-1 & 5.939 & 7.455 & 1.516 \\
\hline D-3 & 2.456 & 2.654 & 0.198 \\
\hline D-4 & 3.661 & 4.463 & 0.802 \\
\hline
\end{tabular}

\subsection{Binding energy and Transition density matrix analysis}

For the evaluation of electro-optical properties and electron-hole pair dissociation potential (efficiency) of organic solar cell materials, binding energy $\left(E_{b}\right)$ is a significant parameter. The columbic forces existing between electron-hole pairs are estimated through the binding energy. Due to low dielectric constant of organic molecules, strong columbic forces between the electron and the hole pair leads to the high binding energy which in turn is in inverse relation to the dissociation energy. Columbic forces and binding energy are directly proportionate. For dissociation of exciton, organic molecules are needed to be introduced with electron acceptor moieties to facilitate the separation of electron-hole pair.

Binding energy of electron-hole pair can be estimated through Eq. (3) [51].

$\left.E_{b}=E_{(L U M O-H O M O)}-E_{(S 1-S O}\right)(3)$

Where $E_{b}$ represents the binding energy or is the estimation of dissociation energy of exciton, $\mathrm{E}_{(\mathrm{LUMO}-\mathrm{HOMO})}$ is band gap energy of optimized organic solar cell material and $\left.\mathrm{E}_{(\mathrm{S} 1-\mathrm{SO}}\right)$ is single point excitation energy difference of the molecule from ground to excited state. Band gap energies, single point excitation energies and their corresponding binding energies in solvent phase are given in the Table 6 . 
Table 6

Binding energies in the gaseous phase and chloroform solvent are shown.

\begin{tabular}{|llllll|}
\hline Molecule & Energy gap $\left(\mathrm{E}_{\mathrm{g}}\right)$ & $\left.\mathrm{E}_{(\mathrm{S} 1-\mathrm{S} 0}\right)$ & $\mathrm{E}_{\mathrm{b}}(\mathrm{eV})$ & $\mathrm{E}_{(\mathrm{S} 1-\mathrm{s} 0)}$ & $\mathrm{E}_{\mathrm{b}}(\mathrm{eV})$ \\
\hline Solvent phase & Solvent phase & Gaseous & Gaseous \\
\hline D-1 & 2.62 & 2.14 & 0.48 & 2.23 & 0.39 \\
\hline D-2 & 2.45 & 2.01 & 0.44 & 2.09 & 0.36 \\
\hline D-3 & 2.54 & 2.06 & 0.48 & 2.16 & 0.38 \\
\hline D-4 & 2.28 & 2.03 & 0.25 & 2.20 & 0.08 \\
\hline
\end{tabular}

It has been observed and inferred from the tabulated results that binding energies in solvent phase are higher than in gaseous phase. The higher binding energies in solvent phase are purely attributed to the solvent interactions that tightly held the electron-hole pairs together. Among the tailored molecules D-3

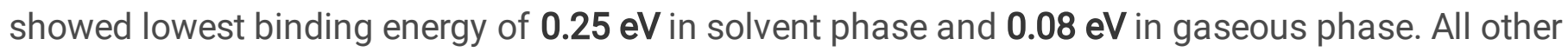
architecture molecules also have lower binding energy values than $\mathbf{R}$.

In molecular systems transition density matrix[52] analysis of filled and simulated orbitals is a significant tool for analyzing electronic excitations. Transition density matrix provides a spatial map which reads off characteristic features like coherence and delocalization lengths. Coherence length is actually separation size or length of distribution of associated electron and hole pair. This characterizing feature is important in demonstrating charge transfer dynamics in light harvesting organic solar cells[53]. Without changing the transition, charge density transformation can be analyzed when electron density is drawn by acceptor moieties from donor core[54]. We visualize the dynamics of shifting of electron density in terms of coherence length indicated by diagonal bright lines in the spatial transition density matrix map shown in Fig. 7.

For better understanding and interpretation of interaction between donor core and terminal end capped acceptor moieties we segmented the molecule into principle components (benzodithiophene donor core D and acceptor components A). Due to the less contribution of hydrogen atoms towards excitations, we ignored them from all architecture molecules. Amongst the rest of atoms, 1-73 atoms in numbering correspond to Benzodithiophene donor core $\mathbf{D}$, while atoms that are numbered above 73 fall in the category of Acceptors (A) which are arranged along Y-axis (left) and X-axis (bottom) in spatial TDM map, whereas, the electron density is on Y-axis (right side). TDM spatial map analysis discloses that electrons are entirely distributed in reference $\mathbf{R}$ from donor core to the end capped acceptor moieties as indicated by diagonally bright line which indicate the coherence between donor and acceptor parts. On the other hand, in tailored molecules D-1, D-2, D-3 and D-4, electron density does not uniformly spread over the 
entire molecule because end capped acceptor moieties are deficient of electrons so there is a uniform trend of electron transfer from donor to acceptor portions as indicated by bright diagonal fringe.

\subsection{Open circuit voltage $\left(V_{o c}\right)$ of OSCs}

Open circuit voltage of organic solar cell is maximum voltage of a photovoltaic cell when there is no load connected to the circuit (zero current level). It is total current drawn from an optical device at null current level of the device. To estimate the photovoltaic properties of OSC material, open circuit voltage is a significant parameter. Performance and efficiency of the optical system greatly depend upon $\mathrm{V}_{\text {oc}}$. Large values of $\mathrm{V}_{\mathrm{oc}}$ increases the fill factor which have major contribution to the efficiency of the system. In this research work we estimated the $\mathrm{V}_{\text {oc }}$ of reference and architecture molecules theoretically in a simulation analysis with $\mathrm{PC}_{61} \mathrm{BM}$. To achieve high open circuit voltage values, the HOMO of the donor molecule should be more de-stabilized with respect to LUMO of acceptor molecule ( $\mathrm{PC}_{61} \mathrm{BM}$ in this case).

Open circuit voltage of molecules is calculated through Eq. (4).

$V_{o c}=\frac{\text { ELUMO Of Acceptor }- \text { EHOMO Of Donor }}{e}-0.3$

$V_{\text {oc }}$ is the function of band gap, increase in band gap energy leads to the large $V_{\text {oc }}$ values until the drop off in the open circuit voltage is observed due to short circuit current. Voltaic strength in term of $V_{\text {oc }}$ of architecture molecules are $2.05 \mathrm{eV}, 1.93 \mathrm{eV}, \mathbf{1 . 9 1} \mathrm{eV}, \mathbf{1 . 8 7} \mathrm{eV}$ and $\mathbf{1 . 7 8} \mathrm{eV}$ for D-1, D-2, D-4, D-3 and R respectively as shown in Fig. 8. These are in line with the difference of individual energies of HOMO of donor molecules and LUMO of fullerene derivative $\mathrm{PC}_{61} \mathrm{BM}$ acceptor molecule. It is concluded from the open circuit voltage simulation analysis that designed molecules have greater values of $\mathrm{V}_{\text {oc }}$ and hence greater power conversion efficiencies than reference, so they are considered as the best choice for organic photovoltaics.

\section{Conclusion}

A series of donor molecules in A-D-A configuration containing fluorinated thienyl substituted benzodithiophene (BDT) donor core connected to 2-methylenemalononitrile in D-1, 2-methylene-3oxobutanenitrile in D-2, 2-(2-methylene-3-oxo-2,3-dihydro-1 H-inden-1-ylidene) malonitrile in D-3 and 3methyl-5methylene-2-2thioxothiazolidin-4-one in D-4 as terminal acceptor moieties have been designed. Electro-optical and photovoltaic properties of architecture molecules were investigated and compared with model molecule R (DRTB-FT) at MPW1PW91/6-31G** level of theory. Reduced energy band and broadened optical absorption was obtained for all architecture molecules. Band gap energies of architecture and reference molecule arrange themselves in the order of $2.62>2.54>2.53>2.45>2.28$ for R, D-2, D-4, D-1 and D-3 respectively. These reduced band gap resulted into broader absorption in the visible region of the spectrum with maximum absorbance at $617 \mathrm{~nm}$ by D-1 molecule. Amongst all the molecules, D-3 architecture molecule has lowest reorganization energy of electron (0.00397 eV) which 
favors better charge mobilities D-3 also showed lowest binding energy of $0.25 \mathrm{eV}$ in solvent phase and $0.08 \mathrm{eV}$ in gaseous phase. All other architecture molecules have comparable binding energy values with the $\mathbf{R}$. The increasing order of solubilities at ground state were 0.853 Debye $(\mathbf{R})<1.556$ Debye $(\mathbf{D}-4)<$ 2.456 Debye (D-2) <3.661 Debye (D-3) $<5.939$ Debye (D-1). All the chromophores exhibited higher value of dipole moment than $\mathbf{R}$ that is attributed to the favorable interaction of polar solvent with these moieties. Voltaic strength in terms of $\mathrm{V}_{\mathrm{oc}}$ of architecture molecules were $2.05 \mathrm{eV}, 1.93 \mathrm{eV}, 1.91 \mathrm{eV}, 1.87 \mathrm{eV}$ and $1.78 \mathrm{eV}$ for D-1, D-2, D-4, D-3 and R respectively. These were in line with the difference of individual energies of $\mathrm{HOMO}$ of donor molecules and LUMO of fullerene derivative $\mathrm{PC}_{61} \mathrm{BM}$ acceptor molecule.

\section{Declarations}

\section{Associated Information}

Supporting information (SI-1) include cartesian coordinates of internally optimized geometries of all molecules (reference R, and architecture molecules D-1, D-2, D-3 and D-4 along X, Y and Z axis at MPW1PW91/6-31G (d, p) level of density functional theory (DFT).

\section{Acknowledgement}

The authors acknowledge the financial and technical support from Punjab Bio-energy Institute (PBI), University of Agriculture Faisalabad (UAF), Pakistan.

\section{Supplementary Information}

Supplementary material file is attached.

\section{Author contributions}

Usama Mubashar performed the performed the computations, Afifa Farhat presented the manuscript draft, Rasheed Ahmad Khera supervised the findings of this work and, Javed Iqbal presented the idea, Rabia Saleem computed the results.

Funding: No funding was received.

\section{Data availability}

The datasets generated during and/or analyzed during the current study are available from the corresponding author on reasonable request.

\section{Compliance with ethical standards}

Ethical approval: Not applicable.

Consent to participate: Not applicable. 
Consent for publication: Not applicable

\section{Author declaration}

The authors declare that they have no conflicts of interest.

\section{References}

1. Rehman A, Deyuan Z (2018) Investigating the linkage between economic growth, electricity access, energy use, and population growth in Pakistan. Applied sciences 8(12):2442

2. Reddy AK et al., Energy and social issues. World energy assessment, 2000: p. 39-60

3. Coyle ED, Simmons RA, Understanding the global energy crisis (2014) Purdue University Press

4. Sabir S et al (2020) Tuning the optoelectronic properties of Benzo Thiophene (BT-CIC) based nonfullerene acceptor organic solar cell. Journal of Theoretical Computational Chemistry 19(01):2050003

5. Jaccard M, Sustainable fossil fuels: the unusual suspect in the quest for clean and enduring energy (2006) Cambridge University Press

6. Bujang A, Bern C, Brumm T (2016) Summary of energy demand and renewable energy policies in Malaysia. Renew Sustain Energy Rev 53:1459-1467

7. Rodríguez XA, Arias C (2008) The effects of resource depletion on coal mining productivity. Energy Econ 30(2):397-408

8. Margat J, Foster S, Droubi A, Concept and importance of non-renewable resources. Non-renewable groundwater resources: A guidebook on socially-sustainable management for water-policy makers, 2006. 10: p. 13-24

9. Davis SJ, Peters GP, Caldeira K, The supply chain of $\mathrm{CO} 2$ emissions. Proceedings of the National Academy of Sciences (2011) 108(45): p. 18554-18559

10. Aye GC, Edoja PE (2017) Effect of economic growth on CO2 emission in developing countries: Evidence from a dynamic panel threshold model. Cogent Economics Finance 5(1):1379239

11. Nordhaus WD, Efficient use of energy resources. 1979

12. Naeem M et al (2019) Tuning of optoelectronic properties of triphenylamines-based donor materials for organic solar cells. Journal of Theoretical Computational Chemistry 18(07):1950036

13. Rosenberg N, The direction of technological change: inducement mechanisms and focusing devices. Economic development and cultural change (1969) 18(1, Part 1): p. 1-24

14. Hart DM, Forged consensus: science, technology, and economic policy in the United States, 19211953. Vol. 65 (1998) Princeton University Press

15. Mondal MAH, Denich M (2010) Assessment of renewable energy resources potential for electricity generation in Bangladesh. Renew Sustain Energy Rev 14(8):2401-2413 
16. Kabir E et al (2018) Solar energy: Potential and future prospects. Renew Sustain Energy Rev 82:894900

17. Yousaf I et al., Isatin-derived non-fullerene acceptors for efficient organic solar cells. Materials Science in Semiconductor Processing. 121: p. 105345

18. Javed MS et al (2016) The energy crisis in Pakistan: A possible solution via biomass-based waste. J Renew Sustain Energy 8(4):043102

19. Erdogdu E (2009) On the wind energy in Turkey. Renew Sustain Energy Rev 13(6-7):1361-1371

20. Farhat A et al (2020) Tuning the optoelectronic properties of Subphthalocyanine (SubPc) derivatives for photovoltaic applications. Opt Mater 107:110154

21. Yue Q, Liu W, Zhu X (2020) $n$-Type molecular photovoltaic materials: design strategies and device applications. J Am Chem Soc 142(27):11613-11628

22. Lim HR et al (2020) Advanced soft materials, sensor integrations, and applications of wearable flexible hybrid electronics in healthcare, energy, and environment. Adv Mater 32(15):1901924

23. Bounioux C, Katz EA, Yerushalmi-Rozen R (2012) Conjugated polymers-carbon nanotubes-based functional materials for organic photovoltaics: a critical review. Polym Adv Technol 23(8):11291140

24. Yao H et al (2016) Molecular design of benzodithiophene-based organic photovoltaic materials. Chemical reviews 116(12):7397-7457

25. Wang E, Mammo W, Andersson MR, 25th Anniversary Article: Isoindigo-Based Polymers and Small Molecules for Bulk Heterojunction Solar Cells and Field Effect Transistors. Advanced Materials (2014) 26(12): p. 1801-1826

26. Mikroyannidis J et al (2011) Low band gap conjugated small molecules containing benzobisthiadiazole and thienothiadiazole central units: synthesis and application for bulk heterojunction solar cells. J Mater Chem 21(12):4679-4688

27. An Q et al (2014) Improved efficiency of bulk heterojunction polymer solar cells by doping lowbandgap small molecules. ACS Appl Mater Interfaces 6(9):6537-6544

28. Scharber MC, Sariciftci NS (2013) Efficiency of bulk-heterojunction organic solar cells. Prog Polym Sci 38(12):1929-1940

29. Liao C-Y et al (2020) Processing strategies for an organic photovoltaic module with over $10 \%$ efficiency. Joule 4(1):189-206

30. Todorov T et al (2015) Monolithic perovskite-CIGS tandem solar cells via in situ band gap engineering. Advanced Energy Materials 5(23):1500799

31. Liu M et al (2020) Naphthalene-Diimide-Based Ionenes as Universal Interlayers for Efficient Organic Solar Cells. Angew Chem Int Ed 59(41):18131-18135

32. Yao $\mathrm{J}$ et al (2020) Cathode engineering with perylene-diimide interlayer enabling over $17 \%$ efficiency single-junction organic solar cells. Nature communications 11(1):1-10 
33. Firdaus $Y$ et al (2019) Key Parameters Requirements for Non-Fullerene-Based Organic Solar Cells with Power Conversion Efficiency > 20\%. Advanced Science 6(9):1802028

34. Cui $Y$ et al (2019) Over $16 \%$ efficiency organic photovoltaic cells enabled by a chlorinated acceptor with increased open-circuit voltages. Nature communications 10(1):1-8

35. Zhan C, Zhang X, Yao J (2015) New advances in non-fullerene acceptor based organic solar cells. RSC Adv 5(113):93002-93026

36. Liu C et al (2020) All-Small-Molecule Organic Solar Cells Based on a Fluorinated Small Molecule Donor With High Open-Circuit Voltage of 1.07 V. Front Chem 8:329

37. Dennington R, Keith TA, Millam JM (2008) GaussView 5, Gaussian. Inc., Wallingford

38. Frisch M et al (2009) gaussian 09, Revision d. 01, Gaussian, 201. Inc., Wallingford

39. Civalleri B et al (2008) B3LYP augmented with an empirical dispersion term (B3LYP-D*) as applied to molecular crystals. CrystEngComm 10(4):405-410

40. Yanai T, Tew DP, Handy NC (2004) A new hybrid exchange-correlation functional using the Coulombattenuating method (CAM-B3LYP). Chemical physics letters 393(1-3):51-57

41. Adamo C, Barone V (1998) Exchange functionals with improved long-range behavior and adiabatic connection methods without adjustable parameters: The $\mathrm{m}$ PW and $\mathrm{m}$ PW1PW models. J Chem Phys 108(2):664-675

42. Chai J-D, Head-Gordon M (2008) Long-range corrected hybrid density functionals with damped atom-atom dispersion corrections. Physical Chemistry Chemical Physics 10(44):6615-6620

43. Yu C, Hao X, Shen Q (2010) Illustration of origin 8.0. Chemical Industry Press, Beijing

44. Shehzad RA et al., Designing of benzothiazole based non-fullerene acceptor (NFA) molecules for highly efficient organic solar cells. Computational and Theoretical Chemistry, 2020: p. 112833

45. Tenderholt A (2006) PyMOlyze, Version 1.1. Stanford University, Stanford

46. Lu T, Chen F (2012) Multiwfn: a multifunctional wavefunction analyzer. J Comput Chem 33(5):580592

47. Marcus RA (1993) Electron transfer reactions in chemistry. Theory and experiment. Rev Mod Phys 65(3):599

48. Fujisawa J-i (2014) An unusual mechanism for HOMO-LUMO gap narrowing in a minimal near-IR dye generated by the deprotonation of bis (dicyanomethylene) indan. Chem Phys Lett 608:355-359

49. Yang L et al (2019) Theoretical studies on 4H-cyclopenta [2, 1-b: 3, 4-b'] dithiophene-based Windmillshaped nanogrids with low reorganization energies. Chem Phys 516:191-198

50. Collado-Fregoso E et al (2015) Increased exciton dipole moment translates into charge-transfer excitons in thiophene-fluorinated low-bandgap polymers for organic photovoltaic applications. Chem Mater 27(23):7934-7944

51. Ans $\mathrm{M}$ et al (2019) Designing indacenodithiophene based non-fullerene acceptors with a donoracceptor combined bridge for organic solar cells. RSC Adv 9(7):3605-3617 
52. Etienne T (2015) Transition matrices and orbitals from reduced density matrix theory. J Chem Phys 142(24):244103

53. Li Y, Ullrich C (2011) Time-dependent transition density matrix. Chem Phys 391(1):157-163

54. Mehboob MY et al., Designing of Benzodithiophene Core-Based Small Molecular Acceptors for Efficient Non-Fullerene Organic Solar Cells. Spectrochimica Acta Part A: Molecular and Biomolecular Spectroscopy, 2020: p. 118873

\section{Figures}


Reference Molecule $\mathbf{R}$

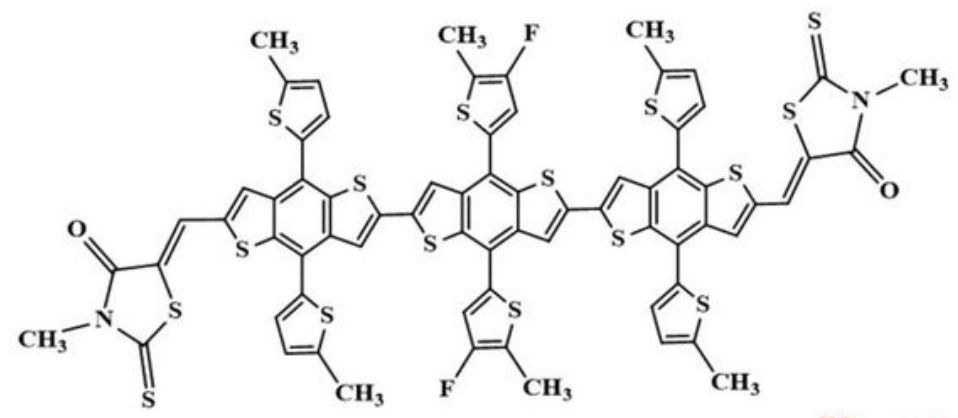

Designed Molecule

D-1
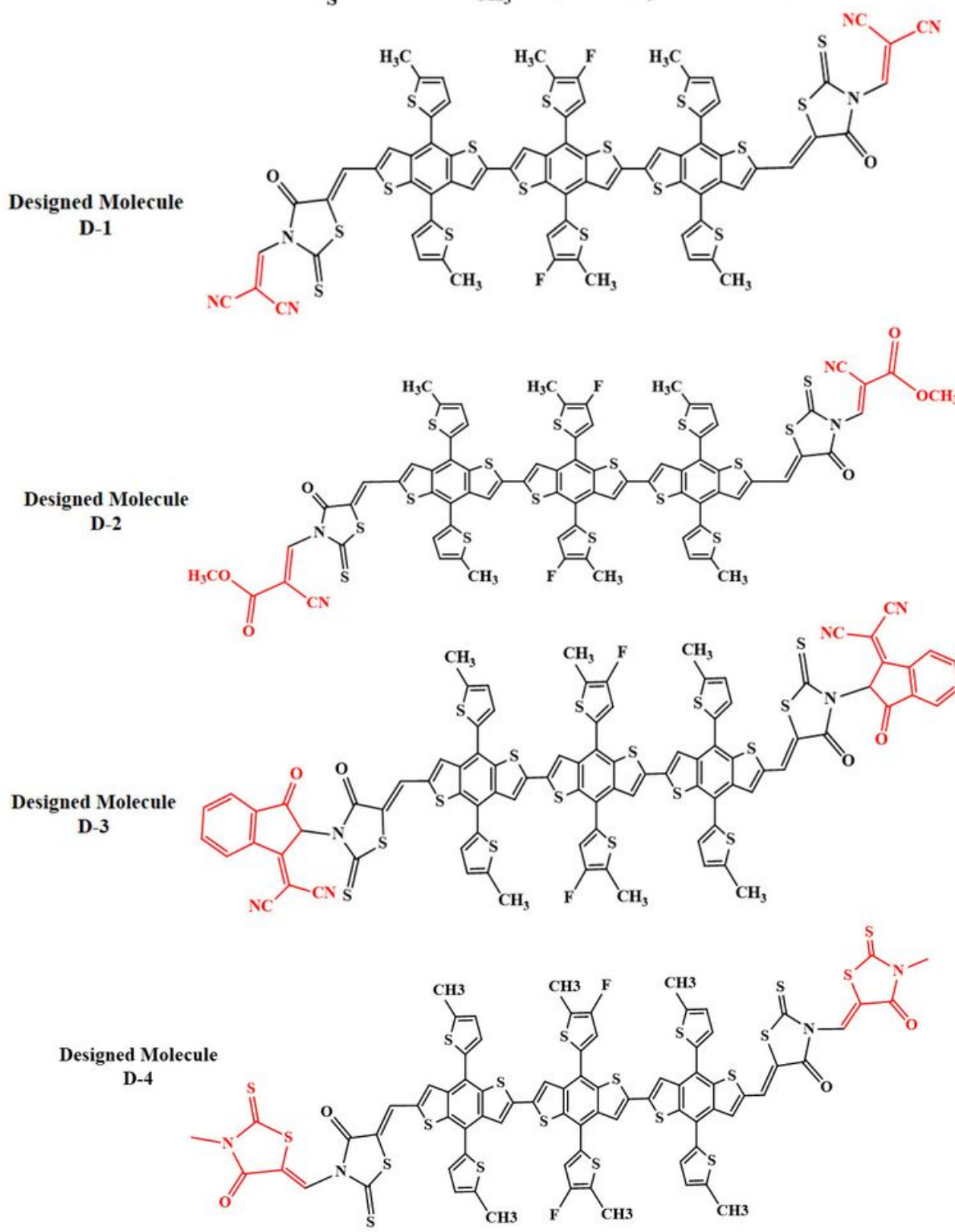

Figure 1

Reference and designed molecule's chemical structures drawn using ChemDraw Ultra12.0. 

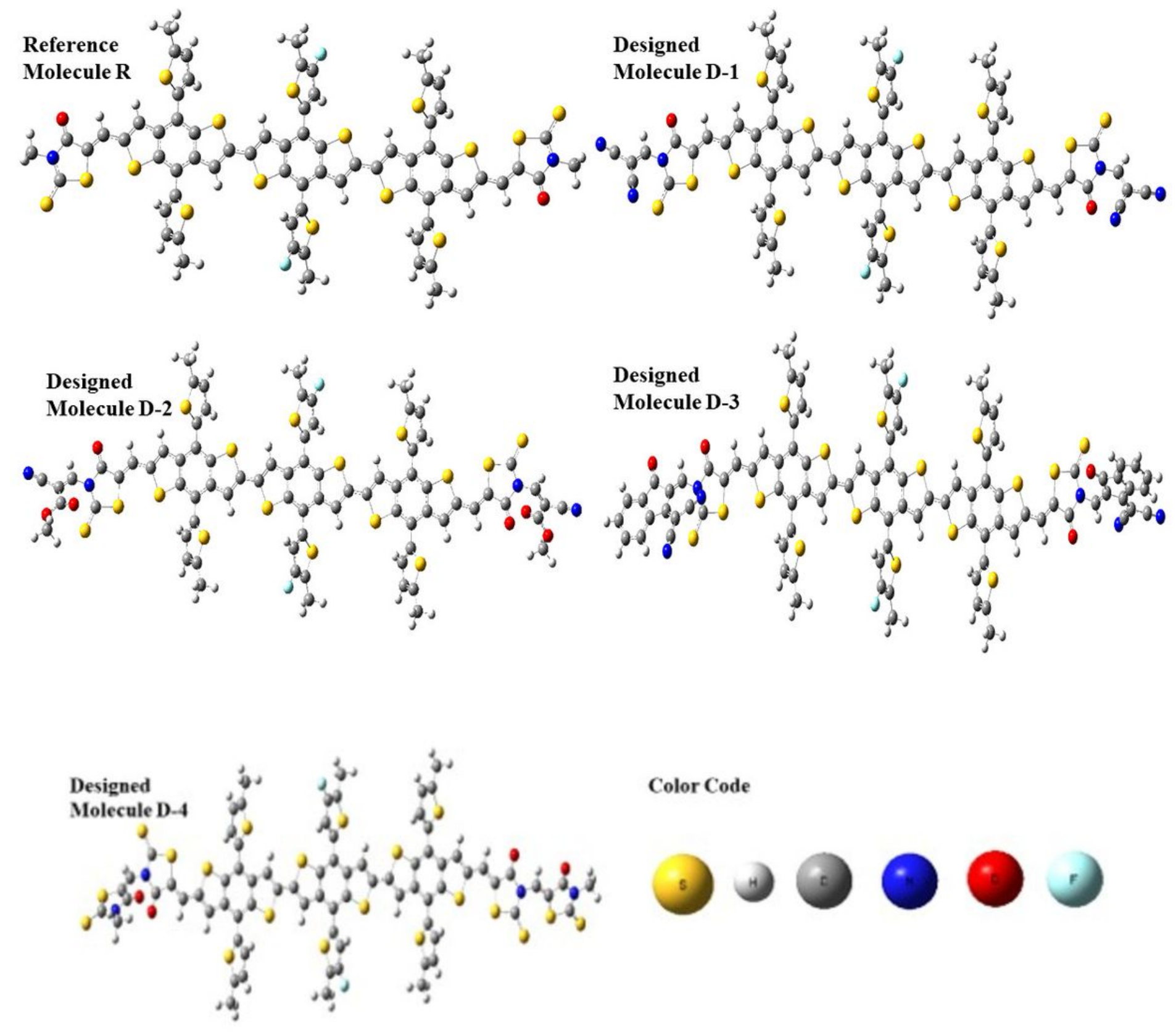

Figure 2

Stable conformations of R and D-1-D-4 with MPW1PW91/6-31G** level of density functional theory. 

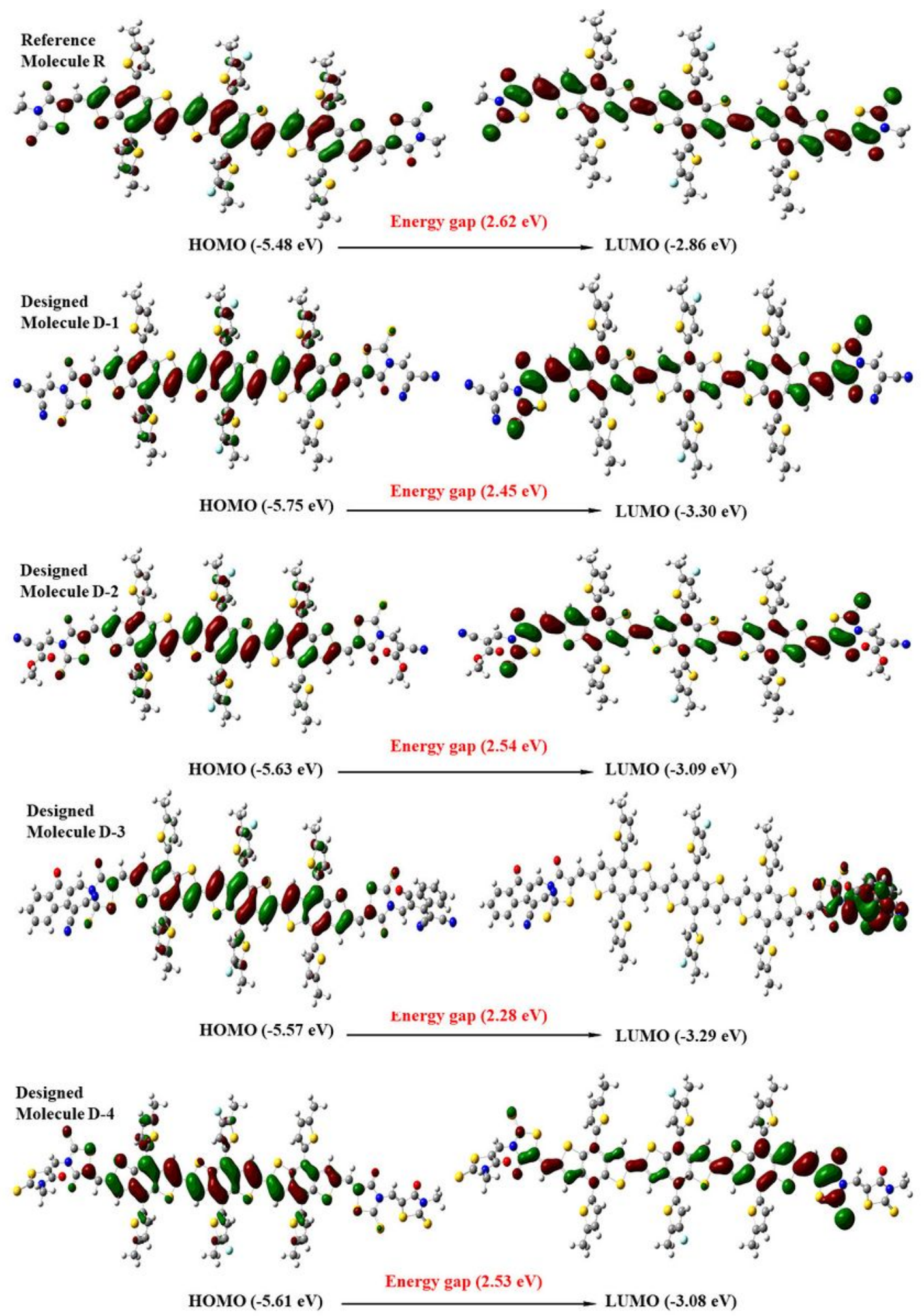

Figure 3

Representation of frontier molecular orbitals (HOMO and LUMO). 


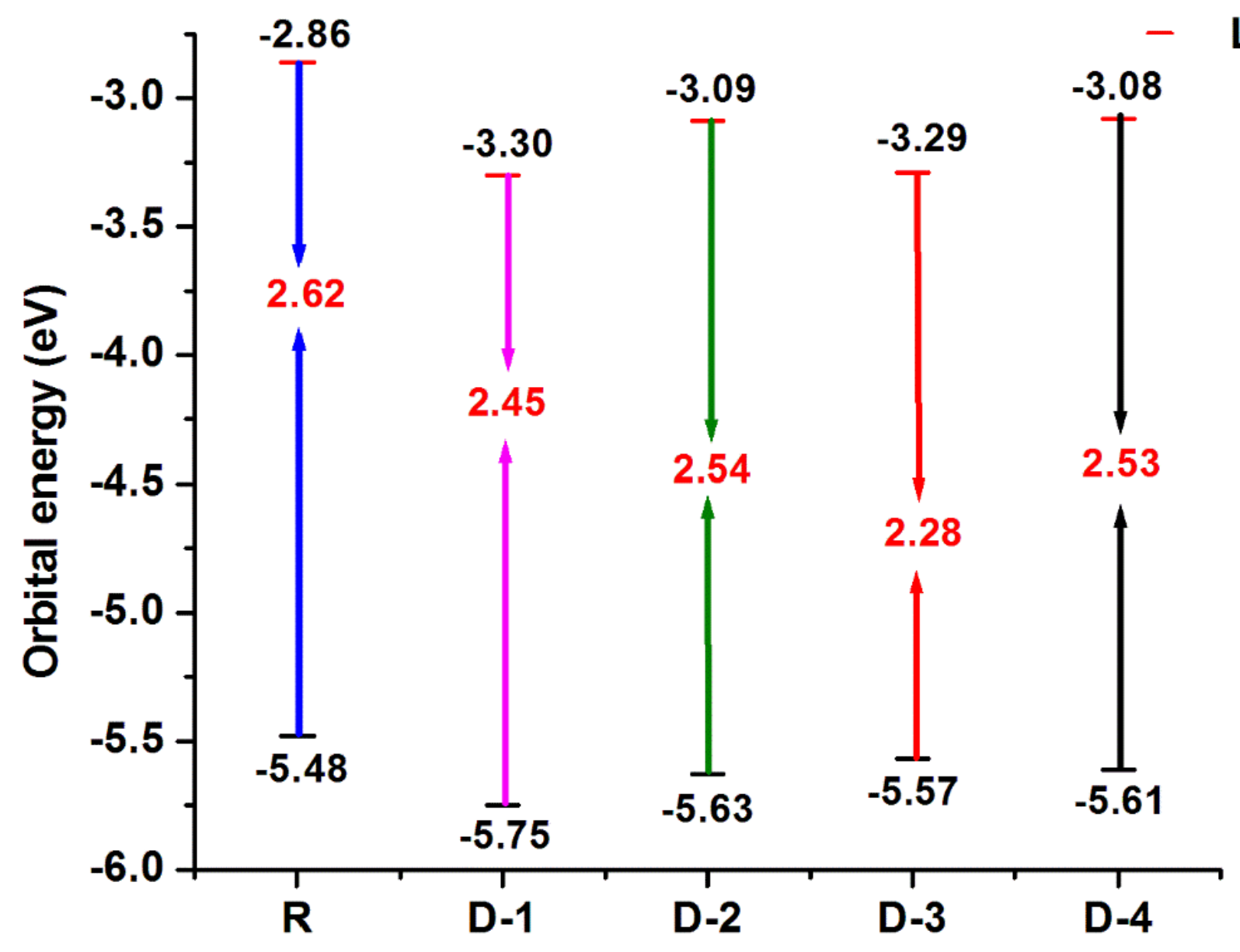

Figure 4

Graphical description of band gap and HOMO, LUMO energy values 

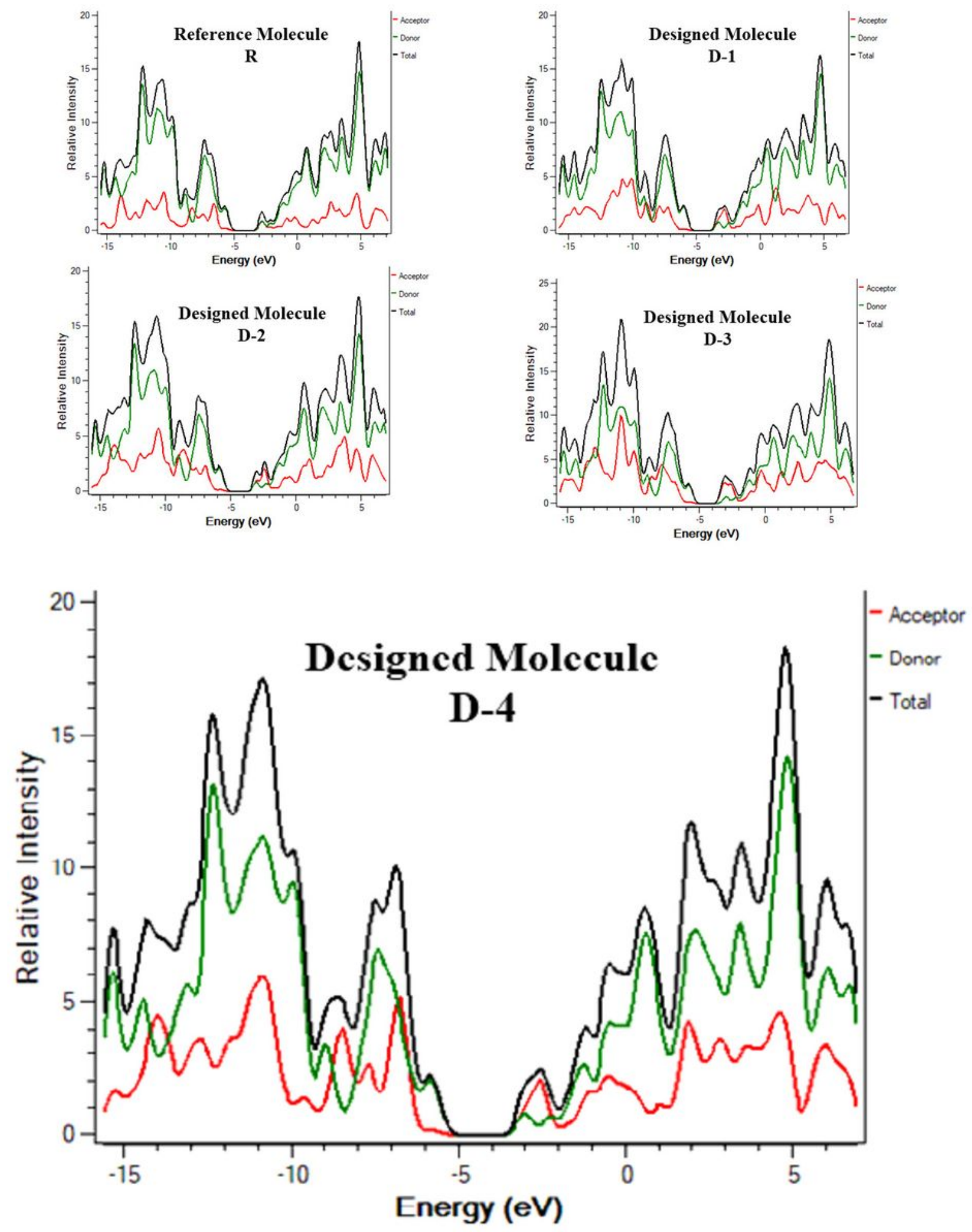

Figure 5

Simulated density of state (DOS) graph of R and designed D-1-D-4 molecules at MPW1PW91/6-31G basis set. 

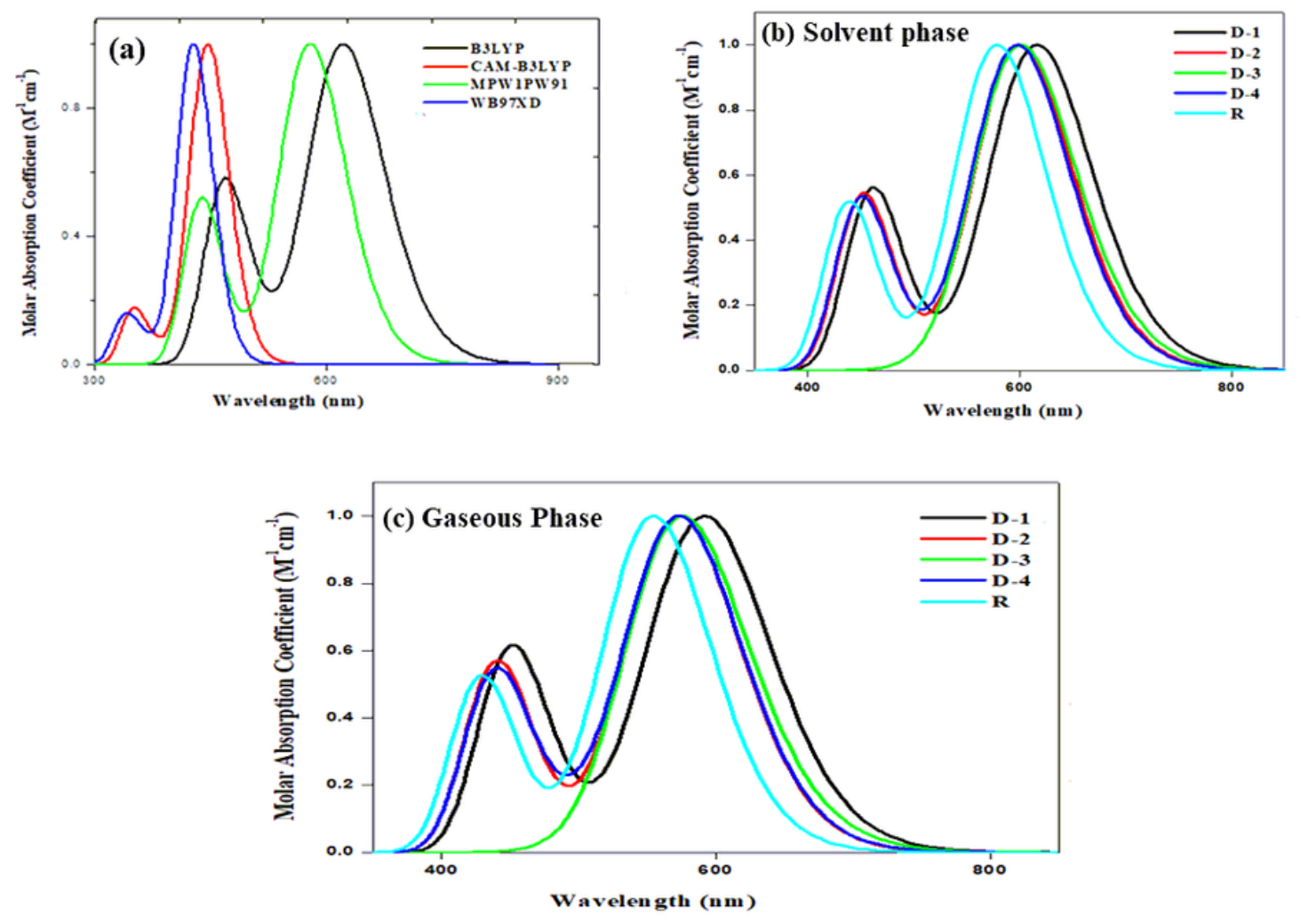

\section{Figure 6}

Simulated absorption spectrums (a) Absorption spectrum of R molecule with different functionals of DFT, (b) absorption spectrum of designed and reference molecule D-1, D-2, D-3, D-4 and R in solvent phase (c) absorption spectrum of D-1, D-2, D-3, D-4 and R in gaseous phase. 

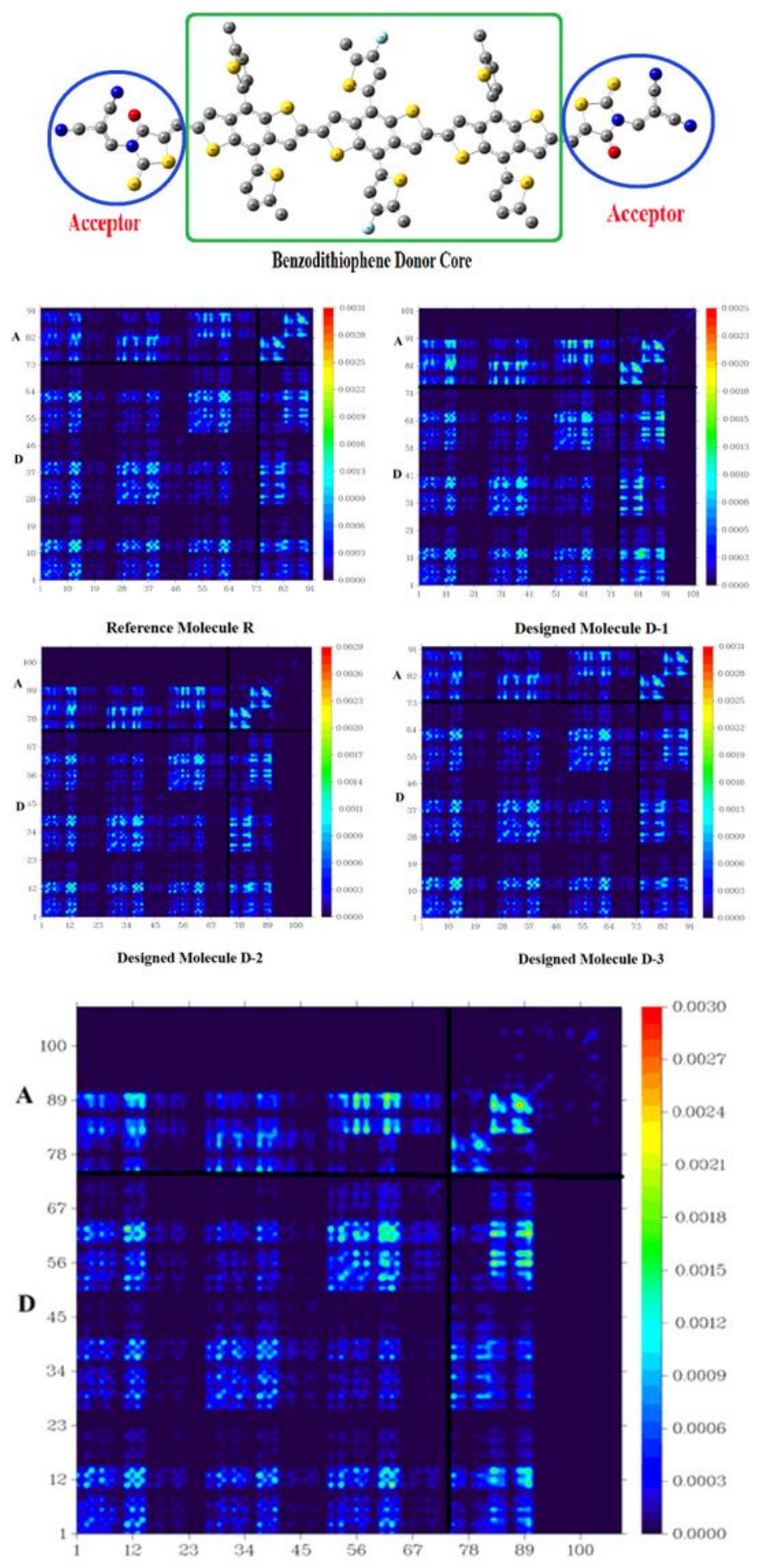

\section{Designed Molecule D-4}

\section{Figure 7}

TDM (transition density matrix) spatial map of all molecules demonstrating electron density distribution pattern from donor core to acceptor moieties. 
L

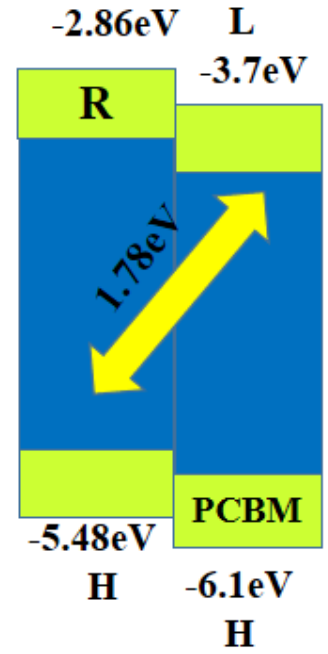

L

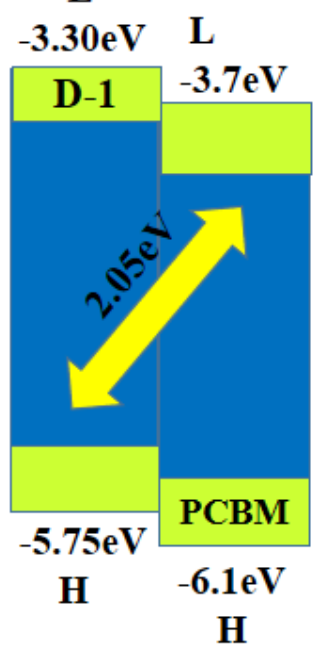

L

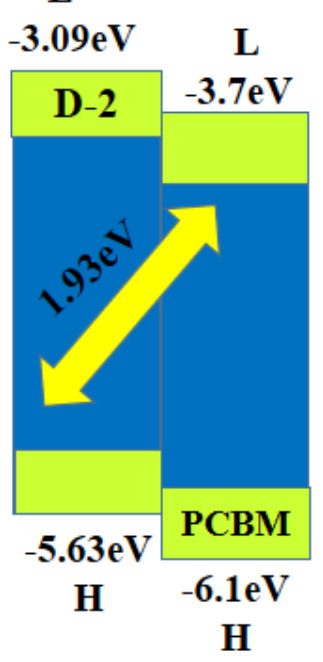

L

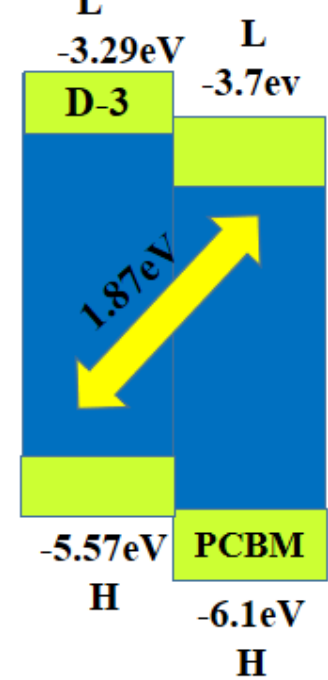

L

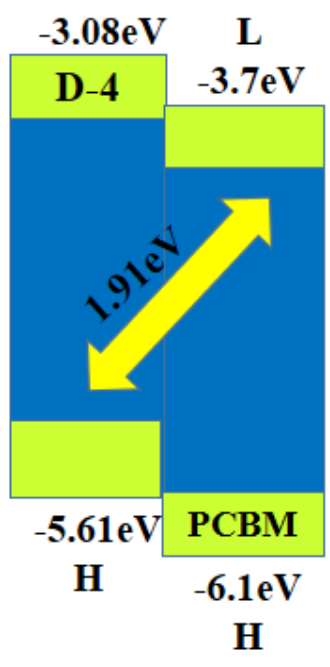

Figure 8

Voc of R and architecture donor molecules with respect to PC61BM acceptor molecule.

\section{Supplementary Files}

This is a list of supplementary files associated with this preprint. Click to download.

- GraphicalAbstract.docx

- SupportingInformation3.docx 